\title{
ANALISIS TINGKAT PEMAHAMAN MATERI SANITASI \\ LINGKUNGAN DENGAN FILM DOKUMENTER PADA \\ MAHASISWA PENDIDIKAN BIOLOGI
}

Asri

Universitas Cokroaminoto Palopo, Palopo, Indonesia

sakkaasri64@gmail.com

\begin{abstract}
Abstrak
Penelitian ini bertujuan untuk meningkatkan pengetahuan tentang pencemaran lingkungan berupa limbah sanitasi, sehingga Mahasiswa Pendidikan Biologi Universitas Cokroaminoto Palopo diberikan pembelajaran menggunakan film dokumenter sebanyak 31 orang. Langkah penelitian adalah metode tindakan pembuatan kit film dokumenter yang divalidasi oleh ahli media pembelajaran agar layak digunakan dan soal evaluasi menggunakan software Google Form untuk dilakukan secara online oleh mahasiswa setelah proses pembelajaran. Kemampuan memahami materi mahasiswa dalam kategori sedang sebanyak 22 orang dari total sampel 31 orang, dengan persentase 71 persen. Kategori rendah pemahaman materi sebanyak 9 orang dengan persentase 29 persen yang artinya kemampuan mahasiswa memahami materi menggunakan film dokumenter masih kurang baik 29 persen. Upaya peningkatan pengetahuan mahasiswa pendidikan biologi tentang masalah sanitasi lingkungan dengan pembelajaran film dokumenter dapat memberikan efek peningkatan pengetahuan lingkungan pada kategori sedang dan beberapa masih rendah. Diharapkan ilmu yang diperoleh dapat memberikan dampak positif bagi lingkungan di masa yang akan datang.
\end{abstract}

Kata Kunci: Peningkatan pengetahuan, film dokumenter, Pendidikan Biologi, Sanitasi Lingkungan, Media Pembelajaran

Published by:

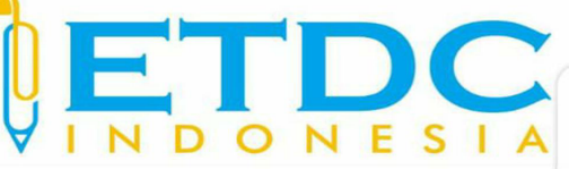

Copyright (C) 2021 The Author (s)

This article is licensed under CC BY 4.0 License (cc) $\mathrm{BY}$ 


\section{ANALISIS TINGKAT PEMAHAMAN MATERI SANITASI LINGKUNGAN DENGAN FILM DOKUMENTER PADA MAHASISWA PENDIDIKAN BIOLOGI}

\section{Pendahuluan}

Pendidikan lingkungan hidup di sekolah-sekolah pemerintah dan swasta sudah lama dirintis sejak Kurikulum Tahun 1984 dengan model pembejaran pendekatan bentuk monilitik dan integrative. Prasetyo (2018) mengemukakan pendidikan lingkungan hidup di sekolah sekolah semakin tidak jelas arahnya temasuk di dalam kurikulum. Tantangan manusia kedepan menghadapi kondisi lingkungan semakin hari semakin berubah kedalam bentuk kerusakan, sehingga akan berdampak pada manusia dan mahluk hidup lainnya. Masyarakat perlu disadarkan termasuk pelajar dan mahasiswa memiliki ilmu pengetahuan, akan tetapi kepedulian terhadap lingkungan masih kurang yang dibuktikan dengan membuang limbah sanitasi tidak pada tempatnya mengakibatkan air tanah tercemar dan menimbulkan bau akan berdampak pada kesehatan manusia. Tantangan dimasa sekarang pemerintah sulit menertibkan masyarakat membuang limbah sanitasi rumah tangga, kegiatan indutri kecil, restoran, pasar tradional dan moderen termasuk areal kampus, Asri (2020). Banyak factor penyebab kerusakan lingkungan salah satunya adalah besarnya popolasi jumlah penduduk, kemiskinan, dan perilaku manusia untuk memperoleh keuntungan sebesar sebarnya disebut mental serakah. Chiras (1991: 457) bahwa mentalitas seseorang berwawasan terhadap lingkungan, yang perlu disikapi harus ada kesadaran, dan prinsip sikap yang dimiliki berorientasi pada generasi mendatang tidak akan mewariskan suatu bencana akibat kerusakan lingkungan.

Pendidikan Lingkungan Hidup (PLH) sudah tidak di ajarakan kepada mahasiswa sebagai bekal mengelola lingkungan dalam kehidupan sehari-hari, sehingga akan berdampak pada perilaku dan pola pikir dalam diri masing-masing yaitu: (1) kerusakan lingkungan karena faktor internal, diakibatkan perilaku manusia yang tidak disadari, sehingga bagi masyarakat secara luas menerima dampaknya karena bencana dari proses alam. Kejadiannya dalam waktu singkat, akan tetapi dampak atau akibat yang diterima dalam waktu lama; (2) kerusakan karena faktor eksternal, yaitu kerusakan lingkungan yang berasal dari perilaku manusia. Perilaku mengusai alam untuk mendapatkan kekayaan peribadi merupakan gaya hidup yang sulit di atasi industri perkebunan, dan pertambangan (Asri, 2019). 
Menyadarkan masyarakat, pelajar, dan mahasiswa diperlukan pendidikan lingkungan, sehingga diterapkan mulai tingkat, SD sampai pada tingkat pergruruan tinggi (Fatima, 2014; Asri, 2016). Program studi yang memiliki kaitan pembelajaran lingkungan hidup adalah mahasiswa Pendidikan Biologi pada Fakultas Keguran dan Ilmu Pendidikan (FKIP) Universitas Cokroaminoto Palopo, yaitu berkaitan pemahaman bagaimana menghasilkan budidaya tanaman yang tidak tercemar akibat limbah sanitasi lingkungan akibat perilaku watak manusia. Rachmad (2009) mengemukakan bahwa ada tiga watak dominan manusia yang perlu dipelajari secara mendalam, yaitu: (1) manusia sebagai penakluk lingkungan, (2) manusia sebagai pejuang lingkungan, (3) manusia sebagai perancang keberlanjutan lingkungan.

Berdasarkan data empiris, terjadinya kerusakan lingkungan akan dipengaruhi tindakan sosial manusia yang tidak terkontrol memungkikan seorang manusia akan memiliki watak seperti yang dikemukakan di atas. Jika watak manusia tidak dibarengi sentuhan pengetahuan, dan pemahaman tentang pengelolaan lingkungan maka perilaku peduli terhadap permasalahan lingkungan sulit untuk teratasi. Untuk itu Soerjani (2009) mengemukakan hasil kerusakan lingkungan disebabkan oleh polluting technology sekitar 75\% ditambah dengan unsur kemiskinan, kebijakan yang kurang tepat, dan kecepatan pertumbuhan penduduk.

Mahasiswa Pendidikan Biologi Universitas Cokroaminoto Palopo sudah memiliki dasar ilmu pengetahaun tentang lingkungan, untuk mengetahui apakah ilmu yang mereka miliki sejalan dengan apa yang terjadi pada lingkungan. Mahasiswa tersebut perlu di evaluasi melalui pembelajaran menggunakan film dokumenter berdasarkan pada fakta yang telah terjadi pada lingkungan akibat dari perilaku pembuangan sanitasi disembarang tempat. Pembelajaran menggunakan film dokumenter untuk disampaikan kemahasiswa pendidikan Biologi dengan materi sanitasi lingkungan menggunakan model pembelajaran tindakan mengacu pada model Elliot, Sukardi (2016).

Desain model pembelajaran tersebut bisanya dijadikan dasar sebagai acuan untuk merencanakan dan melakasanakan pembelajaran yaitu model pembelajaran berbasis media. Adanya perangkat film domenter digunakan sebagai sumber informasi, maka diharapkan: (1) peserta belajar mahasiswa nantinya terbiasa menggunakan pembelajaran memanfaatkan teknologi informasi bentuk media, (2) peserta belajar mahasiswa terbiasa berinteraksi menyimak materi menggunakan media film dokumenter, (3) pembelajaran berbasis media film dokumenter merupakan pembelajaran yang sengaja dirancang dalam bentuk perangkat lunak 
(software). Pembelajaran ini disajikan lewat Zoom dan evaluasi menggunakan google forms untuk mengetahui sejauh mana pemahaman mahasiswa tentang sanitasi lingkungan.

\section{Metode Penelitian}

Jenis penelitian ini penelitian tindakan, bertujuan agar mahasiswa Pendidikan Biologi memiliki kesadaran tidak membuang limbah disembarang tempat, untuk menyadarkan maka diberikan pembelajaran menggunakan film dokumenter. Skardi, (2016) mengemukakan penelitian tindakan ada empat langkah penting yaitu: (1) langkah perencanaan melakukan desain Perencanaan Pembelajaran (RP) sebagai acuan langkah-langkah pembelajaran dan muatan materi film dokumenter berupa gambar-gambar kondisi lingkungan rusak akibat limbah sanitasi lingkungan, dan materi ditambahkan ahli kesehatan mansyarakat. Perencanaan desain film dokumenter menggunakan aplikasi perangkat lunak (software) untuk pembuatan animasi video gambar, dan soal evaluasi; (2) Peninjauan studi kelayakan tentang Perencanaan Pembelajaran RP), dan film dokumenter di validasi ahli untuk kelayakan penggunaannya, hasilnya sangat valid; (3) Perencanaan mengacu pada pembuatan Rencana Pembelajaran (RP) beserta tahapan-tahapannya, dan perencanaan pembuatan Film Dokumenter beserta materimateri yang disajikan; (4) Tindakan, implementasi pembelajaran menggunakan film dokumenter pada Mahasiswa Pendidikan Biologi semester 3 sebanyak 31 orang sebagai sampel. Implementasi keterlaksanaan pembelajaran lingkungan menggunakan film dokumenter mengacu pada model Elliot (Sukardi, 2016), tahapannya dapat dilihat pada Gambar 1 sebagai berikut.

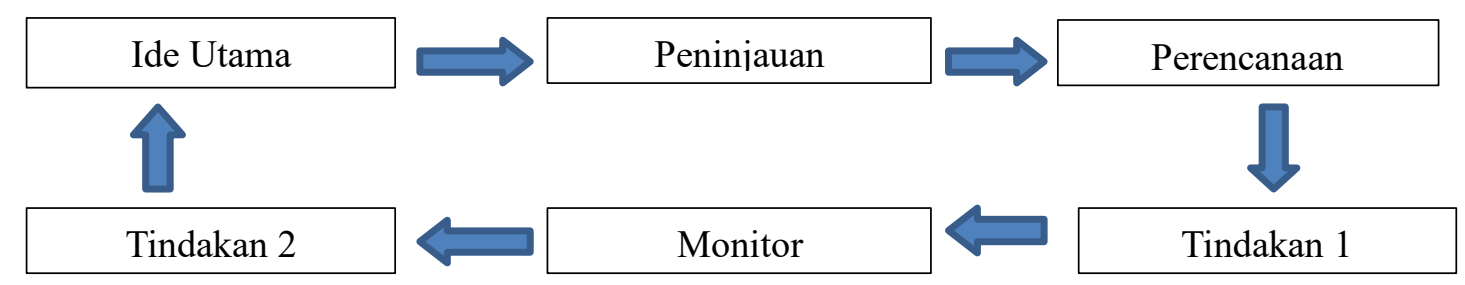

Gambar 1. Siklus Model Elliot

Teknik analisis data yang digunakan adalah analisis data deskriptif untuk melihat ukuran pemusatan dan ukuran penyebaran data, dan uji statistika menentukan kategori penguasaan materi sanitasi lingkungan. Analisis penguasaan materi sanitasi lingkungan yang diperoleh dari mahasiswa data skor. Menurut Winkel (2019) penskoran hasil belajar dapat dilakukan menggunakan kriteri sebagai berikut: 
$10=$ amat buruk, 20 = buruk, $30=$ amat kurang, $40=$ kurang, $50=$ tidak cukup, $60=$ cukup, $70=$ lebih dari cukup, $80=$ baik, $90=$ amat baik, $100=$ istimewa

Menentukan kategori kemampuan memahami bahan ajar materi sanitasi lingkungan terhadap mahasiswa Pendidikan Biologi sebagai berikut:

$$
\begin{aligned}
& 85 \leq \bar{X} \leq 100: \text { Kemampuan sangat tinggi } \\
& 65 \leq \bar{X}<85: \text { Kemampuan tinggi } \\
& 45 \leq \bar{X}<65: \text { Kemampuan sedang } \\
& 25 \leq \bar{X}<45: \text { Kemampuan rendah } \\
& <25 \text { Kemampuan sangat rendah, Winkel, (2019) }
\end{aligned}
$$

\section{Hasil dan Pembahasan}

\section{a. Validasi Perangkat Film Dokumenter}

Film dokumenter di validasi oleh ahli multimedia sebagai perangkat yang digunakan dalam pembelajaran untuk meningkatkan pengetahuan tentang sanitasi lingkungan pada Mahasiswa Pendidikan Biolgi. Validasi hali tujuannya untuk memenuhi kelayakan film dokumenter yang digunakan sebagai media pembelajaran. Hasil validasi film dokumenter dapat dilihat pada Gambar 2 sebagai berikut:

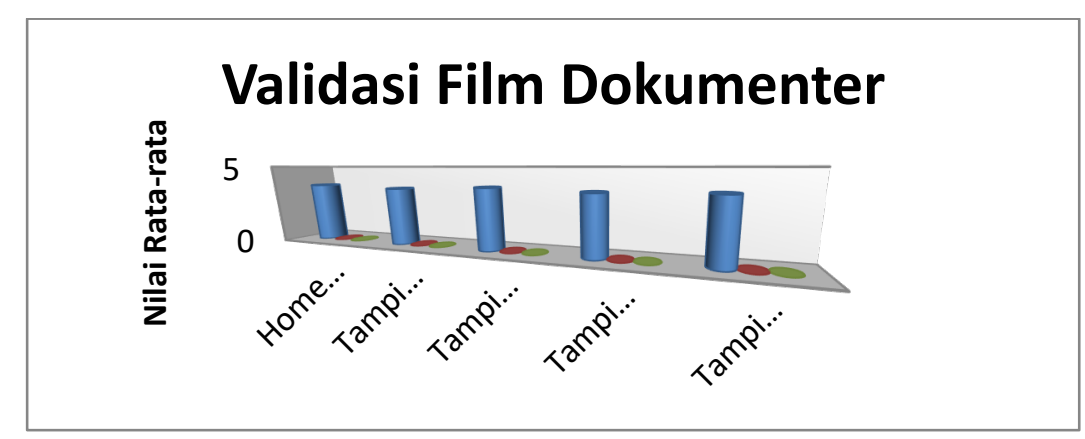

Gambar 2. Validasi Film dokumenter

Hasil validasi Gambar 2 di atas, ahli multimedia pembelajaran telah memberikan penilaian kelayakan penggunaan film dokumenter yang digunakan sebagai alat bantu penyampaian materi sanitasi lingkungan terhadap Mahasiswa Pendidikan Biologi, hasilnya dapat dikemukakan sebagai berikut:

1. Home (Tampilan awal), yang dinilai ahli adalah desain tampilan menu utama, tampilan menu judul, tampilan menu materi pokok-pokok bahasan, tampilan menu soal pilihan ganda, dan tampilan menu petunjuk penggunaan film dokumenter dalam pembelajaran 
dengan skor nilai rata-rata sebesar $\bar{X}=3,75$ angka tersebut dalam penentuan

2. Kriteria kevalidan memenuhi unsur valid, maka disimpulkan Home sebagai tampilan awal film dokumenter digunakan dalam proses belajar pada kategori "Sangat Valid"

3. Tampilan film Dokumenter, yang dinilai ahli adalah tampilan kualitas warna, tampilan kualitas teks, tampilan kualitas gambar, tampilan kualitas audio dengan skor nilai ratarata sebesar $\bar{X}=3,62$ angka tersebut dalam penentuan kriteria kevalidan memenuhi unsur valid, maka disimpulkan kualitas tampilan film dokumenter digunakan dalam proses belajar pada kategori "Sangat Valid"

4. Tampilan Materi, yang dinilai ahli adalah durasi waktu digunakan penyajian materi, tampilan materi hutan mangrove, tampilan materi sanitasi lingkungan, tampilan materi limbah domestic, tampilan materi rumah layak huni dengan skor nilai rata-rata sebesar $\bar{X}=3,8$ angka tersebut dalam penentuan kriteria kevalidan memenuhi unsur valid, maka disimpulkan kualitas tampilan materi film dokumenter digunakan dalam kegiatan prosen pembelajaran pada kategori "Sangat Valid".

5. Tampilan soal evaluasi, yang dinilai ahli adalah penggunaan kalimat sederhana dan mudah dimengerti, tampilan bentuk pertanyaan soal, tampilan jawaban soal pilihan ganda, dan tampilan durasi waktu mengerjakan soal dengan skor nilai rata-rata sebesar $\bar{X}=3,66$ angka tersebut dalam penentuan kriteria kevalidan memenuhi unsur valid, maka disimpulkan kualitas tampilan soal digunakan sebagai alat evaluasi pembelajaran pada kategori " Sangat Valid"

6. Tampilan akhir segment (penutup), yang dinilai ahli adalah tampilan ucapan terima kasih sebagai sumber pendanaan, nama peneliti, editor film, dan pengisi suara film dengan skor nilai rata-rata sebesar $\bar{X}=3,75$ angka tersebut dalam penentuan kriteria kevalidan memenuhi unsur valid, maka disimpulkan tampilan akhir segment (penutup) film dokumenter digunakan dalam proses pembelajaran pada kategori "Sangat Valid".

\section{b. Validasi Perangkat Renvcana Pembelajaran (RP)}

Perangkat Rencana Pembelajaran (RP), sebagai pedoman menyusun materi yang akan disampaikan ahli sanitasi lingkungan, termasuk didalamnya memuat langkah-langkah pelaksanan pembelajaran. Pakar pendidikan yang ditunjuk secara cermat melakukan penilaian tentang isi Rencana Pembelajaran (RP), adapun hasil penilian ahli pendidikan dapat dilihat pada 
Tabel 1 berikut:

Tabel 1. Hasil Penilaian Rencana Pembelajaran (RP)

\begin{tabular}{lll}
\hline Aspek yang Dinilai & Nilai Rata-rata $(\overline{\boldsymbol{X}})$ & Status \\
\hline Tujuan Pembelajaran & 4,0 & S. Valid \\
$\begin{array}{l}\text { Materi yang disajikan } \\
\text { Sarana alata bantu }\end{array}$ & 3,8 & S. Valid \\
pembelajaran & 4,0 & S. Valid \\
$\begin{array}{l}\text { Metode dan kegiatan } \\
\text { pembejaran }\end{array}$ & 3,7 & S. Valid \\
Total rata-rata & & \\
\hline
\end{tabular}

Ahli pendidikan sebagai validator Rencana Pembelajaran (RP) memberikan penilaian sebagaimana pada Tabel 1 di atas. Rencana pembelajaran hal yang penting dibuat sebagai pedoman pelaksanaan pembelajaran menggunakan media film dokumenter, penjelasan hasil penilaian ahli dikemukakan sebagai berikut:

1. Komponen Tujuan pembelajaran, komponen ini memuat indikator tujuan pembelajaran sani-tasi lingkungan. Ahli memberikan penilaian komponen tujuan pembelajaran yang disusun dalam 3 fase, yaitu: fase 1 pendahuluan: menyiapkan alat tulis, tempat duduk, laptop, LCD, dan perhatian menyimak materi. Fase 2 Kegiatan inti: penjelasan strategi belajar menggunakan media film dokumenter, dan menyimak materi setiap pokok bahasan durasi waktu 30 menit. Fase 3 mengerjakan soal evaluasi hasil belajar menggunakan soal pilihan ganda meggunakan aplikasi zoom. Hasil penilaian ahli pendidikann komponen tujuan pembelajaran yang memuat 3 fase di rata-ratakan sebesar $\bar{X}=4,0$ angka tersebut dalam penentuan kriteria kevalidan memenuhi unsur valid. Maka disimpulkan bahwa komponen tujuan pembelajaran memuat 3 fase kegiatan pembelajaran kelompok nelayan pada kategori "Sangat Valid".

2. Komponen materi, Ahli memberikan penilaian materi yang disajikan oleh kesehatan masyarakat tentang sanitasi lingkungan dan limbah domestik dengan nilai skor rata-rata sebesar $\bar{X}=3,8$, angka tersebut dalam penentuan kriteria kevalidan memenuhi unsur valid. Maka disimpulkan bahwa komponen materi yang dicantumkan dalam RP pada kategori “ Sangat Valid".

3. Komponen Sarana alat bantu pembelajaran, Ahli pendidikan memberikan penilaian sarana alat bantu pembelajaran yang digunakan dalam kegiatan proses belajar yaitu : film doku- 
menter, SD-ROM, Komputer, dan Liquid Crystal Display (LCD) di rata-ratakan sebesar $=4,0$ angka tersebut dalam penentuan kriteria kevalidan memenuhi unsur valid. Maka disim-pulkan bahwa sarana alat bantu untuk digunakan kegiatan pembelajaran pada kategori " San-gat Valid".

4. Metode dan kegiatan pembelajaran, Ahli pendidikan memeberikan penilaian metode yang digunakan yaitu: fase pendahuluan kelompok nelayan diberi arahan kesiapan mengikuti pembelajaran, dan memberikan informasi petunjuk belajar, fase kegiatan inti diarahkan kelompok nelayan menyimak materi melalui film dokumenter, dan fase kegiatan akhir kelompok nelayan diberikan pertanyaan secara lisan untuk dijawab, dan mengerjakan soal bentuk pilihan ganda. Ahli memberikan penilaian dengan rata-rata sebesar $\bar{X}=3,7$ angka tersebut dalam penentuan kriteria kevalidan memenuhi unsur valid. Maka disimpulkan bahwa metode yang digunakan dalam kegiatan pembelajaran pada kategori " Sangat Valid".

\section{c. Hasil Belajar}

Berdasarkan hasil penelitian pembelajaran materi sanitasi lingkungan menggunakan media film dokumenter mahasiswa Pendidikan Biologi. Tabel 1 dikemukakan hasil analisis statsitik jumlah responden mahasiswa yang mengikuti tes 31 orang tujuannya untuk mendapatkan gambaran sejauhmana pemahaman materi sanitasi lingkungan yang semalama ini mereka sudah pernah dapatkan mulai pada tingkat pendidikan dasar sampai perguruan tinggi yang berkiatan dengan disiplin ilmu mereka tekuni selama ini. Gambaran hasil belajar ini diperoleh yang telah dijadikan sampel penelitian dapat dilihat pada Tabel 2 berikut ini.

Tabel 2. Statistik Skor Hasil Belajar Sanitasi Lingkungan

\begin{tabular}{lc}
\hline \multicolumn{1}{c}{ Uraian } & Nilai Statistik \\
\hline N Valid & 31 \\
Mean & 59.387 \\
Std. Error of Mean & 1.3840 \\
Median & 60.000 \\
Mode & 60.0 \\
Std. Deviation & 7.7057 \\
Variance & 59.378 \\
Skewness & .128 \\
Std. Error of Skewness & .421 \\
Kurtosis & -.525 \\
Std. Error of Kurtosis & .821 \\
Range & 30.0
\end{tabular}




\begin{tabular}{lc}
\hline Uraian & Nilai Statistik \\
\hline Minimum & 45.0 \\
Maximum & 75.0 \\
Sum & 1841.0 \\
\hline
\end{tabular}

Hasil analisis tatistik deskriptif Tabel 2 di atas menunjukkan bahwa nilai skor rata-rata sebesar 59,3. Artinya perolehan skor ini secara umum digambarkan rata-rata mahasiswa Pendidikan Biologi hanya mampu memperoleh skor 59,3 tentang materi sanitasi lingkungan selama ini mereka sudah dapatkan lewat bacaan atau saksikan lewat panca indra kondisi lingkungan rusak. Perolehan skor yang masih tergolong rendah tersebut dapat diartikan mahasiswa masih kurang termotivasi memahami materi sanitasi lingkungan untuk digunakan dalam kehidupan seharai harai. Median merupakan nilai tengah, artinya terdapat 50 persen dari nilai menjadi sampel memperoleh skor sanitansi lingkungan sebesar 60. Artinya perolehan skor median hampir sama dengan perolehan nilai rata-rata yang diperoleh mahasiswa, sehingga akan berdampak motivasi memahami materi sanitasi lingkungan untuk digunakan dalam kehidupan sehari harai juga kategori rendah. Mode sebesar 60 menunjukkan bahwa skor sanitasi lingkungan sebesar 60 merupakan skor yang paling banyak di peroleh mahasiwa Pendidikan Biologi. Skor maksimum 75 merupakan skor yang paling tertinggi dirai oleh peserta belajar, artinya sebagian mahasiwa ada yang menyadari bahwa ilmu tentang sanitasi lingkungan perlu diketahui untuk memperbaiki kondisi lingkungan agar terhindar dari pencemaran lingkungan. Skor terendah sebesar 45, menunjukkan bahwa materi sanitasi lingkungan mereka masih kurang memahami, sehingga diperkirakan kemampuan mengelola santasi lingkungan dalam kehidupan sehari-hari juga rendah.

Menentukan kategori dan persentase hasil belajar dikemukakan Winkel (2019), yaitu kategori sangat tinggi, tinggi, sedang, rendah, dan sangat rendah. Kategori hasil belajar dikemukakan hanya pada kategori sedang dan rendah yang diperoleh hasil belajar Mahasiswa Pendidikan Biologi yang berdasarkan hasil pengelompokan nilai, berikut ini disajikan pada Tabel 3 dan Gambar 3 di bawah ini.

Tabel 3. Skor dan kategori hasil belajar dengan film dokumenter

\begin{tabular}{lllll}
\hline No & Skor & Kategori & Frekuensi & Persentase \\
\hline 1 & $45-64$ & Sedang & 22 & $71 \%$ \\
2 & $25-44$ & Rendah & 9 & $29 \%$ \\
\hline
\end{tabular}




\section{Hasil belajar dengan film dokumenter}

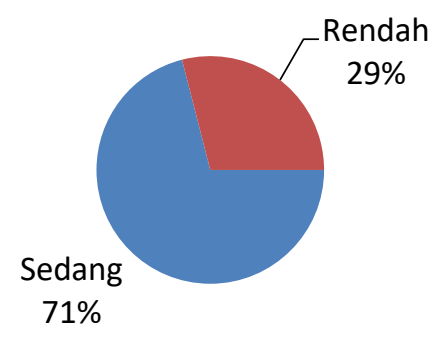

Gambar 3. Kategori hasil belajar sanitasi lingkungan

Pembelajaran menggunakan film dokumenter sebagai metode informasi yang diukur adalah aspek keberhasilan belajar memahami materi sanitasi lingkungan. Mengukur keberhasilan memahami materi untuk menentukan kategori hasil belajar mahasiswa dan besaran persentase yang dimiliki. Tabel 3 menunjukkan bahwa kemampuan mahasiswa memahami materi kategori sedang sebanyak 22 orang dari jumlah sampel 31 orang, artinya kemampuan mahsiswa Pendidikan Biologi memahami materi sanitasi lingkungan berada pada kategori sedang dengan persentase 71 persen. Kategori rendah sebanyak 9 orang dengan pertentase 29 persen, artinya kemampuan memahami materi sanitasi lingkungan menggunakan film dokumenter kurang baik sehingga memperoleh hasil kategori rendah. Mahasiswa Pendidikan Biologi sepantasnya menguasai materi sanitasi lingkungan pada kategori tinggi karena sejalan dengan disiplin ilmu mereka tekuni, mereka sudah dapatkan informasi mulai dari pendidian dasar sampai pada perguruan tinggi. Calon guru Pendidikan Biologi sangat stragesis dimasa akan datang setelah menjadi guru menjelaskan bahaya dampak yang ditimbulkan akibat limbah sanitasi, dan jenis limbah pencemaran lainnya. Sudah lama dunia menyuarakan tentang bahaya ditimbulkan akibat pembuangan limbah termasuk limbah sanitasi, untuk mencegah kerusakan lingkungan akibat limbah harus melalui pemahaman dengan pendidikan. Deklarasi Ahmedabad mengamanatkan bahwa implementasi Pendidikan Lingkungan Hidup dengan agenda yang bersifat permohonan atau imbauan agar seluruh masayarakat di dunia menyadari dan memahami perlunya pendidikan lingkungan hidup sebagai upaya memperkecil timbulnya kerusakan lingkungan, maka di Tasmania Australian system pendidikan lingkungan hidup pada abad ke- 21 mempersyaratkan berlangsung pendidikan untuk kebermaknaan sesuai kebutuhan manusia, dan isi Piagam Bumi tahun 2000 diproklamasikan seluruh penghuni bumi ada 
kewajiban untuk memajukan dan pengembangkan pendidikan lingkungan (Prasetyo, 2018). Tingkat pemahaman yang rendah tentang pengetahuan lingkungan maka akan berdampak pada kerusakan lingkungan akibat perbuatan mahasiswa itu sendiri, cara yang terbaik mengingatkan tidak lagi lewat metode ceramah yang selama ini mereka selalu dapatkan, akan tetapi melalui kesadaran stimulus pembelajaran lingkungan menggunakan media interaktif model film dokumenter sebagai metode informasi. Pembelajaran lingkungan model film dokumenter di desain untuk mengukur stimulus kemampuan ingatan (kognitif), melalui ingatan dapat memiliki makna tersimpan dalam memori peserta belajar berdasarkan kasus- kasus gambar kerusakan lingkungan dibuat dalam bentuk gambar, suara, dan animasi (Sharon, 2012; Made, 2011).

\section{Kesimpulan}

Penerapan pembelajaran menggunakan film dokumenter sebagai metode informasi dapat bermanfaat pada Mahasiswa Pendidikan Biologi untuk merubah cara berpikir mengelola lingkungan, diharapkan dapat merubah untuk tidak lagi membuang limbah Sanitasi Lingkungan disembarang tempat dapat mencemari air tanah. Mahasiswa Pendidikan biologi memperoleh hasil belajar kategori sedang sebanyak 71 persen memahami pencemaran limbah sanitasi lingkunga, tingkat pemahaman tersebut dijadikan bekal untuk menyampaikan ke perta didiknya saat melakukan proses pembelajaran di kelas akan datang. Informasi masalah lingkungan yang terjadi melalui pembelajaran penting dilakukan untuk menyelamatkan generasi akan dantang.

\section{DAFTAR PUSTAKA}

Armitage, A., Evershed, J., \& Hayes, D. (2012). Teaching and training in lifelong learning. McGraw-Hill Education (UK).

Asri, A., Junaid, R., \& Saputra, S. (2019). ANALISIS MODEL BELAJAR LINGKUNGAN HIDUP MENGGUNAKAN VIDEO DOKUMENTER SEBAGAI METODE INFORMASI PADA PENDUDUK PESISIR KABUPATEN LUWU TIMUR. In Seminar Nasional Hasil Penelitian \& Pengabdian Kepada Masyarakat (SNP2M) (pp. 44-49).

Asri, A., Junaid, R., \& Saputra, S. (2020). The Development of Learning Model through Video Documentary to Improve Environmental Knowledge of Coastal Residents of Palopo City, Indonesia. Jurnal Pendidikan IPA Indonesia, 9(3), 396-407. 
Asri, A., Rusdiana J., \& Saddang, S. (2019). Model Belajar Lingkungan Pesisir dan Etika Pengelolaan Wilayah Gowa Sulawesi Selatan. Global Research and Consulting Institute (Global-RCI) Anggota IKAPI.

Asri, A. (2016). Pendidikan Lingkungan Hidup di SMK Berbasis Teknologi Informasi. Gowa Sulawesi Selatan. Global Research and Consulting Institute (Global-RCI) Anggota IKAPI.

Chiras, D. D. (1991). Environmental Science: Action for a Sustainable Future. alifornia: The Benyamin. Cummings Pub.

Prasetyo \& Hariyanto, (2018). Indonesia environmental education (Basic pedagogy and methodology). Bandung. PT. Remaja Rosdakarya Indonesia, ISBN: 9786024461867

Rachmad, K. (2009). Sosiologi lingkungan. Jakarta: PT RajaGrafindo.

Smaldino, S. E., Lowther, D. L., Russell, J. D., \& Mims, C. (2008). Instructional technology and media for learning. Terjemahkan oleh: Arif Rahman. Jakarta: Pranada Media Group Indonesia. ISBN: 9786028730594.

Soerjani, M. (2009). Pendidikan Lingkungan: Sebagai Dasar Sikap dan Perilaku Bagi Kelangsungan Kehidupan Menuju Pembangunan Berkelanjutan. Jakarta: UI-Press

Sukardi. (2016). Educational research methodology. PT.Bumi Aksara. ISBN: 979-526-852-X.

Viteri, F., Clarebout, G., \& Crauwels, M. (2014). Children's recall and motivation for an environmental education video with supporting pedagogical materials. Environmental Education Research, 20(2), 228-247.

Wena, M. (2009). Strategi pembelajaran inovatif kontemporer suatu tinjauan konseptual operasional. Jakarta: bumi aksara.

Winkel, W. S. (1996). Psikologi pendidikan. Jakarta: Grasindo. 